\title{
FERROCENYL ALKYLAMMONIUM N-SUBSTITUTED POLYPYRROLE CONTAINING Pt AND Pd AND ITS APPLICATION ON ELECTROANALYSIS OF ARSENITE
}

\author{
JULIO SÁNCHEZ ${ }^{*}$, BERNABÉ L. RIVAS ${ }^{2}$,JEAN-CLAUDE MOUTET ${ }^{3}$, DIEGO P. OYARZÚN ${ }^{4}$ \\ ${ }^{\text {I}}$ Departamento de Ciencias del Ambiente, Facultad de Química y Biología, Universidad de Santiago de Chile, USACH, Casilla 40, Correo 33, Santiago, Chile. \\ ${ }^{2}$ Polymer Department, Faculty of Chemistry, University of Concepción, Casilla 160-C, Concepción, Chile. \\ ${ }^{3}$ DCM, Université Grenoble Alpes, CNRS, F-38000 Grenoble, France. \\ ${ }^{4}$ Centro de Nanociencias Aplicadas (CENAP), Facultad de Ciencias Exactas, Universidad Andrés Bello, Chile, Avenida República 275, Santiago, Chile.
}

\section{ABSTRACT}

Arsenic occurs in a variety of forms and oxidation states and is a very toxic element. The main inorganic arsenic species present in natural waters are arsenate (oxidation state V) and arsenite ions (oxidation state III). Arsenite is more toxic and mobile than arsenate. Therefore, it is important the development of new materials for analysis and control of these toxic species.

This research proves that polymer-metal composite electrode materials synthesized by incorporation of $\mathrm{Pt}^{0}$ and $\mathrm{Pd}^{0}$ nanoparticles into a poly(pyrrole-ferrocenyl alkylammonium) matrix present electrocatalytic properties towards the oxidation of arsenite to arsenate.

The polymer films displayed a stable electrochemical response in aqueous solution. However, when the polymer film modified electrode were transferred to aqueous solution in presence of arsenite anions, the CV curves for polymer films were deeply modified by the decrease in the electroactivity of the film. It can be concluded that the cationic polymer films present a strong affinity toward arsenite anions. The composite films containing $\mathrm{Pt}^{0} \mathrm{or} \mathrm{Pd}^{0}$ showed catalytic activity towards oxidation of $\mathrm{As}(\mathrm{III})$ to $\mathrm{As}(\mathrm{V})$ due to the presence of metal catalyst particles into the polymer films.

Keywords: Arsenic; Electroanalysis; Modified Electrodes; Functionalized Polypyrrole; Composite Films.

\section{INTRODUCTION}

Arsenic is a ubiquitous element that ranks $20^{\text {th }}$ in abundance in the crust of earth, $14^{\text {th }}$ in the seawater, and $12^{\text {th }}$ in the human body. ${ }^{1}$ Arsenic has been used in medicine, agriculture, livestock, electronics, industry, and metallurgy., ${ }^{2,3}$ It is now well recognized that consumption of arsenic, even at low levels, is highly toxic. ${ }^{4,5}$

The maximum permissible concentration in Europe and accepted by the World Health Organization for arsenic in drinking water is $10 \mu \mathrm{g} \mathrm{L}{ }^{-1}$. On the other hand, developing countries are struggling to find and implement systems to reach the standard of $50 \mu \mathrm{g} \mathrm{L}-1$ in areas affected by the presence of arsenic. ${ }^{6}$

Arsenic exists in four oxidation states: $-3,0,+3$ and +5 with oxidized $\mathrm{As}(\mathrm{III})$ and $\mathrm{As}(\mathrm{V})$ as the most widespread forms in nature. Carbon forms organoarsenicals with both the trivalent and pentavalent forms. ${ }^{7}$

The main arsenic species present in natural waters are arsenate (oxidation state $\mathrm{V}$ ) and arsenite ions (oxidation state III) related to the arsenic acid $\left(\mathrm{H}_{3} \mathrm{AsO}_{4}\right)$ and arsenous acid $\left(\mathrm{H}_{3} \mathrm{AsO}_{3}\right)$ respectively. However, the forms, concentrations, and relative proportions of $\mathrm{As}(\mathrm{V})$ and $\mathrm{As}(\mathrm{III})$ in water vary significantly according to changes in input sources such as $\mathrm{pH}$ and oxidation potential. At high redox potential arsenic is stabilized as series of pentavalent (arsenate) oxy-arsenic species: $\mathrm{H}_{3} \mathrm{AsO}_{4} \mathrm{H}_{2} \mathrm{AsO}_{4}^{-}, \mathrm{HAsO}_{4}^{2-}$, and $\mathrm{AsO}_{4}{ }^{3-}$ whereas under most reducing conditions and low redox potential, the trivalent arsenic species $\left(\mathrm{H}_{3} \mathrm{AsO}_{3}, \mathrm{H}_{2} \mathrm{AsO}_{3}^{-}, \mathrm{HAsO}_{3}{ }^{2-}\right.$ and $\left.\mathrm{AsO}_{3}{ }^{3-}\right)$ become stable. ${ }^{8}$

The importance of arsenic detection and monitoring is a very well recognized fact that is emphasized by the extensive studies carried out in this area, entirely dedicated to various aspects of arsenic exposure in the nature. ${ }^{5}$ Different determination methods of inorganic arsenic have been developed over the past 40 years providing timely and efficient risk assessments of inorganic arsenic contamination worldwide. Due to their versatility and miniaturization, electroanalytical techniques have been of great interest in monitoring arsenic contamination on site. Electrochemical techniques have proven to be able to give reliable results in laboratory conditions and as such have potential for further development into mobile, low cost analytical devises capable of fulfilling the requirements of a rapid and accurate sensor. ${ }^{9}$

Some studies have already reported the arsenic detection using voltammetric techniques, mainly anodic and cathodic stripping voltammetry at various electrode materials, including mercury films, gold, and platinum electrodes. ${ }^{10}$ Moreover, direct oxidation of As(III) to As(V) species on platinum electrodes has also been used for the detection of arsenic(III), especially to avoid the interferences observed with stripping voltammetry in presence of multiple metallic species. ${ }^{10-13}$ Besides, it has been shown that the use of platinum nanoparticles modified carbon electrodes results in better sensitivity than platinum macroelectrodes for arsenic sensing. ${ }^{14}$
The present research is focused on developing new systems based on platinum and palladium metal-polyammonium nanocomposites film modified electrodes able to promote the oxidation of $\mathrm{As}(\mathrm{III})$ into $\mathrm{As}(\mathrm{V})$ for detection in the stability domain of the solvent.

\section{EXPERIMENTAL}

\subsection{Materials and equipments}

All electrochemical experiments were carried out using an EGG PAR model 273 potentiostat equipped with an $x-y$ recorder. A standard threeelectrode cell was used for analytical experiments. Potentials are referred to the $\mathrm{Ag} \mid \mathrm{AgCl}$ in $3 \mathrm{M} \mathrm{KCl}$ reference electrode in aqueous electrolytes, and to the $\mathrm{Ag} \mid \mathrm{Ag}^{+} 10^{-2} \mathrm{M}$ in $\mathrm{CH}_{3} \mathrm{CN}+10^{-1} \mathrm{M}$ tetra-n-butylammonium perchlorate (TBAP, Fluka puriss). The glassy carbon disc electrodes ( $3 \mathrm{~mm}$ diameter) were polished with $1-\mu \mathrm{m}$ diamond paste. All experiments were performed at room temperature under an argon atmosphere.

Potassium tetrachloroplatinate and palladate, and acetonitrile (Rathburn HPLC grade S) were used as received. TBAP was dried under vacuum at $80^{\circ} \mathrm{C}$ for 3 days. Distilled water $(5 \mathrm{M} \Omega \mathrm{cm})$ was obtained from an Elgastat water purification system.

2.2. Preparation of the monomer

The monomer ferrocenyl alkylammonium N-substituted pyrrole (Fc-pyr) (see Figure 1) was prepared according to a previously reported procedure. ${ }^{15}$ Equimolar mixtures of (dimethylamino)methylferrocene and iodopropylpyrrole were stirred for $2 \mathrm{~h}$ at $60^{\circ} \mathrm{C}$. The yellow precipitates formed were collected by suction filtration and washed with acetone to give the iodide salt of structure Fc-pyr in $74 \%$ yield. The tetrafluoroborate salts of structure Fc-pyr were obtained by ion-exchange chromatography on Amberlite IRA 93 column in its $\mathrm{BF}_{4}^{-}$form. ${ }^{15}$

2.3. Synthesis and electrodeposition of ferrocenyl alkylammonium $\mathrm{N}$-substituted polypyrrole films (C|poly Fc)

The synthesis of composite electrode materials was carried out by the dispersion by electro-precipitation of noble metal micro/nanoparticles into poly(pyrrole-alkylammonium) films coated onto carbon electrodes, which will display strong electrocatalytic properties towards the oxidation of arsenite to arsenate. The procedure used for the electrosynthesis of the nanocomposite film modified electrodes is shown on Figure 1.

The polymer films (denoted ClpolyFc) can be grown by repeated cyclic voltammetry scans over the -0.2 to $0.9 \mathrm{~V}$ potential range, from unstirred $4 \times$ $10^{-3} \mathrm{M}$ solutions of monomer Fc-pyr respectively, in $\mathrm{CH}_{3} \mathrm{CN}$ containing $10^{-1}$ $\mathrm{M}$ TBAP as supporting electrolyte. The increase in current with each cycle of a multisweep CV is a direct measure of the increase in the surface of the redoxactive polymer. Typically, 15 to 30 cycles were used to grow films containing 
0.5 to $1 \times 10^{-9} \mathrm{M} \mathrm{cm}^{-2}$ of ferrocene units.

Polymer films were also grown by potentiostatic oxidative electropolymerization at $+0.85 \mathrm{~V}$ vs. $\mathrm{Ag} \mid \mathrm{Ag}^{+} 10^{-2} \mathrm{M}^{15}$ Polymerization experiments were controlled through the anodic charge recorded during the electrolysis.

\section{Electropolymerization of pyrrole-alkylammonium monomer}
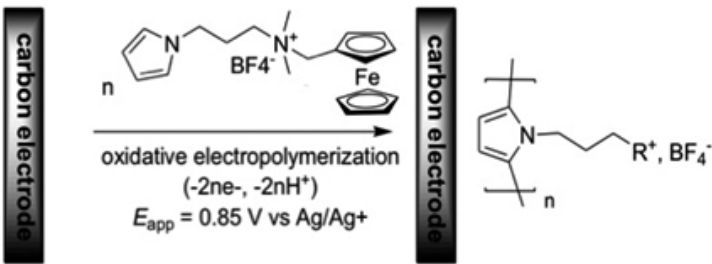

2. Inclusion by ion exchange of a metal salt $(M=P t, P d)$

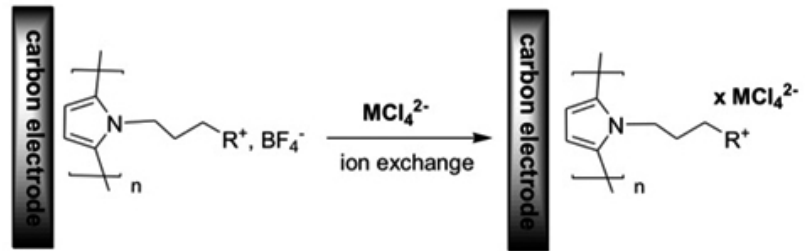

3. Electroreductive precipitation of $M(0)$ nanoparticles

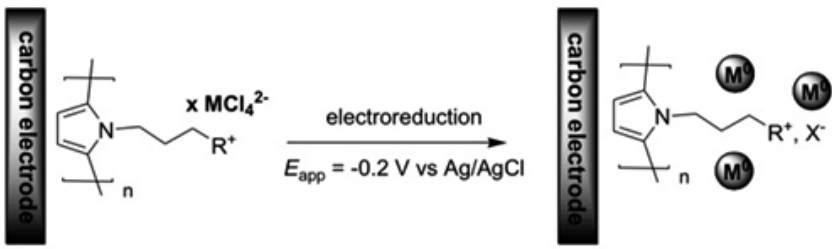

Figure 1. Scheme of electrochemical strategies for synthesis of catalytic nanocomposite electrode materials in three steps. 1) Oxidative electropolymerization at $+0.85 \mathrm{~V} \mathrm{vs} . \mathrm{Ag} / \mathrm{Ag}^{+}$of $4 \times 10^{-3} \mathrm{M}$ solutions of monomer Fc-pyr monomer in $\mathrm{CH}_{3} \mathrm{CN}$ containing $10^{-1} \mathrm{M}$ TBAP as supporting electrolyte. 2) Incorporation by ion exchange of inorganic anions in the polymer film by soaking the ClpolyFc modified electrodes for $30 \mathrm{~min}$ into $10^{-3} \mathrm{M}^{-1} \mathrm{~K}_{2} \mathrm{PtCl}_{4}$ or $\mathrm{K}_{2} \mathrm{PdCl}_{4}$ aqueous solutions containing $10^{-1} \mathrm{M} \mathrm{Na}_{2} \mathrm{SO}_{4}$. 3) Electroreductive precipitation of $\mathrm{M}^{0}$ nanoparticles by controlled potential at $-0.2 \mathrm{~V} \mathrm{vs}$. $\mathrm{Ag} \mid \mathrm{AgCl}$ in the same solution.

\section{RESULTS AND DISCUSSION}

\subsection{Electrochemical characterization}

As already reported, the resulting modified electrodes transferred to clean $\mathrm{CH}_{3} \mathrm{CN}$ electrolyte display a stable electrochemical response (see Figure 2) for the ferrocene $(\mathrm{Fc})$ center at $\mathrm{E}_{1,2}=+0.26 \mathrm{~V}(\Delta \mathrm{E}=0.01 \mathrm{~V}$ at $0.05 \mathrm{~V}$ $\left.\mathrm{s}^{-1}\right)$. No clear redox peak system due to the electroactivity of the polypyrrole matrix could be detected on the CV curves. Obviously, in polyFc films part of the conductivity of the polypyrrole matrix is destroyed following some overoxidation. ${ }^{15}$ Nevertheless, a small wave corresponding to some residual polypyrrole electroactivity may be hidden under the large $\mathrm{Fc} / \mathrm{Fc}^{+}$redox peak system. The apparent surface concentration was determined by recording $\mathrm{CV}$ curve, between +0.1 and $+0.4 \mathrm{~V}$ at $10 \mathrm{mV} \mathrm{s}^{-1}$ in $\mathrm{CH}_{3} \mathrm{CN}$ electrolyte solution and by measuring the charge $\mathrm{Q}_{\mathrm{a}}$ under the anodic peak $\left(\Gamma=\mathrm{Q}_{\mathrm{a}} /(1.3 \mathrm{FA})\right.$ where $\mathrm{F}=96500 \mathrm{C}, \mathrm{A}=$ area of the electrode and taking account of 1.3 exchange electron per monomer - one for the ferrocene center and 0.3 for the polypyrrole center). ${ }^{16}$ The results are summarized in Table 1.

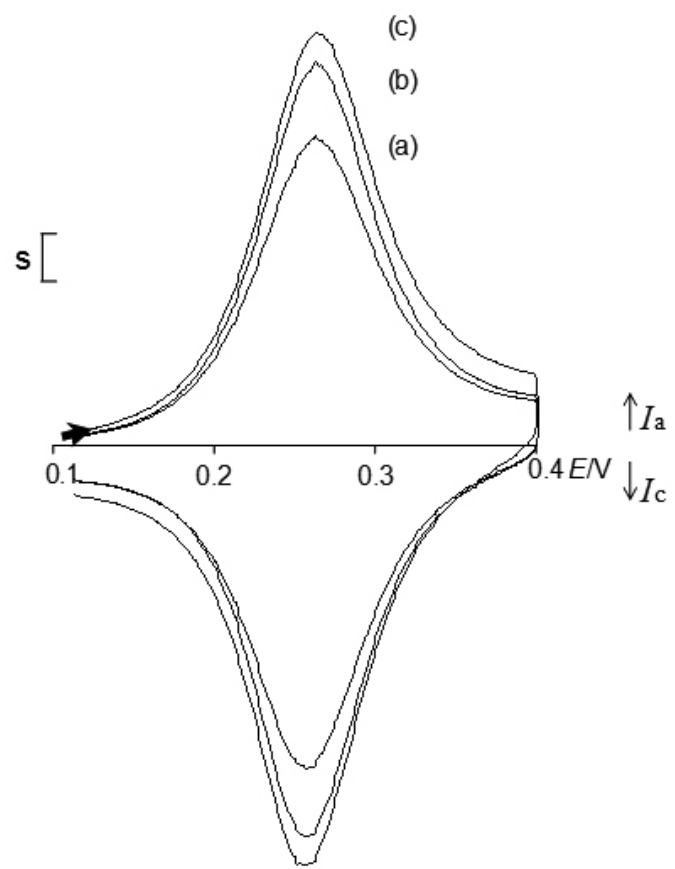

Figure 2. Cyclic voltammetry curves recorded $\left(10 \mathrm{mVs}^{-1}\right.$ in $\mathrm{CH}_{3} \mathrm{CN}$ containing $0.1 \mathrm{M}$ TBAP as supporting electrolyte) for $\mathrm{C}$ polyFc modified electrodes synthesized using $4 \times 10^{-3} \mathrm{M}$ of monomer at $+0.85 \mathrm{~V}$ at different polymerization charges: (a) 1 , (b) 2 and (c) $3 \mathrm{mC}$ respectively. $\mathrm{S}=0.25 \mu \mathrm{A}$.

Table 1. Apparent surface coverage in function of polymerization charge applied.

\begin{tabular}{|c|c|c|c|}
\hline $\begin{array}{c}\text { Polymerization } \\
\text { Charge } \\
\mathbf{Q}_{\mathrm{p}}(\mathbf{m C})\end{array}$ & $\begin{array}{c}\text { Anodic } \\
\text { Charge }_{\mathbf{a}}(\mathbf{C})\end{array}$ & $\begin{array}{c}\text { Number of } \\
\text { Fc sites }\end{array}$ & $\begin{array}{c}\boldsymbol{\Gamma} \\
\left(\mathbf{m o l ~ c m}^{-2}\right)\end{array}$ \\
\hline 1 & $7.34 \times 10^{-6}$ & $5.9 \times 10^{-11}$ & $8.4 \times 10^{-10}$ \\
\hline 2 & $8.12 \times 10^{-6}$ & $6.5 \times 10^{-11}$ & $9.2 \times 10^{-10}$ \\
\hline 3 & $9.13 \times 10^{-6}$ & $7.3 \times 10^{-11}$ & $1.0 \times 10^{-9}$ \\
\hline
\end{tabular}

3.2. Electrocatalytic oxidation of $A s(I I I)$ to $A s(V)$ with different metalpolymer film modified electrodes

It is very well recognized that redox-active polymers could offer useful application for the development of new electrochemical sensors devices. ${ }^{17,18}$ The aim of these systems is convert the interactions at molecular levels into measurable electrochemical signals. In this context, we have performed preliminary investigations on the sensing properties of materials of the type ClpolyFc- $\mathrm{M}^{0}$, synthesized by the incorporation of $\mathrm{Pt}^{0}$ and $\mathrm{Pd}^{0}$ particles into (ferrocenyl methyl)trialkylammonium films synthesized by the oxidative polymerization of the pyrrole-substituted monomer Fc-pyr (see experimental part).

In order to compare the behavior of the ClpolyFc, ClpolyFc- $\mathrm{Pt}^{0}$ and $\mathrm{C} \mid$ polyFc- $\mathrm{Pd}^{0}$ towards arsenite oxidation and sensing, different experiments using these systems have been carried out.

First, a ClpolyFc modified electrode was transferred to aqueous $1 \times$ $10^{-1} \mathrm{M} \mathrm{LiClO}_{4}$ and its electrochemical behavior was examined in using cyclic voltammetry (CV). In Figure $3 \mathrm{~A}$ (curve a) it is observed the stable electrochemical response of the ferrocene center $(\mathrm{Fc})$ at $+0.48 \mathrm{~V}$ vs $\mathrm{Ag} /$ $\mathrm{AgCl}$. After that, when the electrode was transferred to a $1 \times 10^{-1} \mathrm{M}$ aqueous $\mathrm{LiClO}_{4}$ containing $\mathrm{H}_{2} \mathrm{AsO}_{3}^{-}$anions, the $\mathrm{CV}$ curve for $\mathrm{C} \mid$ polyFc is deeply modified, showing a strong decrease in the electroactivity of the film (see Fig. $3 \mathrm{~A}$ curve b). When transferred again into clean $\left(\mathrm{H}_{2} \mathrm{AsO}_{3}^{-}\right.$-free) aqueous solution, the original electroactivity of the film was not fully restored. It can be thus concluded that cationic ClpolyFc film presents affinity toward $\mathrm{H}_{2} \mathrm{AsO}_{3}^{-}$. The loss of electroactivity in presence of $\mathrm{H}_{2} \mathrm{AsO}_{3}^{-}$can be explained by the irreversible doping of the $\mathrm{C}$ polyFc film by $\mathrm{H}_{2} \mathrm{AsO}_{3}^{-}$anions, which is 
responsible for a restricted transport of counterion, and thus to a decrease in the rate of charge propagation in the film. As already noticed for the other redox polymer film, the charge propagation in $\mathrm{C} \mid$ polyFc appears dominated by the counterion diffusivity in the film and ion trapping effects. ${ }^{15}$ As in homogeneous solution strong ion pairs are formed between alkylammonium group and $\mathrm{H}_{2} \mathrm{AsO}_{3}{ }^{-}$in the reduced state of the film, and the ion-pairing is strongly reforced in the oxidized ferrocenium form. It is possible that the increase in the electron density around the $\mathrm{Fc}$ centers stabilizes the $\mathrm{Fc}^{+}$form. Thus, the behavior of CpolyFc in presence of $\mathrm{H}_{2} \mathrm{AsO}_{3}{ }^{-}$is similar to previous reports about poly(ferrocenylalkylammonium)-film modified electrodes in the presence of $\mathrm{H}_{2} \mathrm{PO}_{4}^{-} \cdot 15,17$

In contrast, after the incorporation of platinum particles into $\mathrm{C} \mid$ poly $\mathrm{Fc}$ films, the peak current for the ferrocene center for the resulting C|polyFc- $\mathrm{Pt}^{0}$ nanocomposite-film modified electrode remains essentially the same (about 2 $\mu \mathrm{A}$ ) in the absence (see Figure 3B, curve a) and in the presence (see Figure 3B, curve b) of $10^{-3} \mathrm{M} \mathrm{H}_{2} \mathrm{AsO}_{3}^{-}$. Moreover a clear increase in the anodic current is observed in the presence of arsenite (see Figure $3 \mathrm{~B}$, curve $\mathrm{b}$ ). This behavior is different to that observed with the Pt-free $\mathrm{C} \mid$ polyFc modified electrode. It can be thus assumed that the arsenite ions diffusing into the polymer are catalytically oxidized by $\mathrm{Pt}^{0}$ particles into the polymer film. Therefore, the redox activity of the ferrocene moieties is no more blocked by the irreversible doping of the cationic film with arsenite ions, unlike in the case of the metal-free film (see Figure $3 \mathrm{~A}$ ), and the current measured in the anodic region corresponds to the addition of the oxidation of $\mathrm{Fc}$ centers and that of arsenite. As we will see in the following, the anodic current recorded at $+0.48 \mathrm{~V}$ will allow an accurate measurement of the oxidation of As(III) species, and thus of their concentration, thanks to the well-behaved oxidation peak of the ferrocene groups.

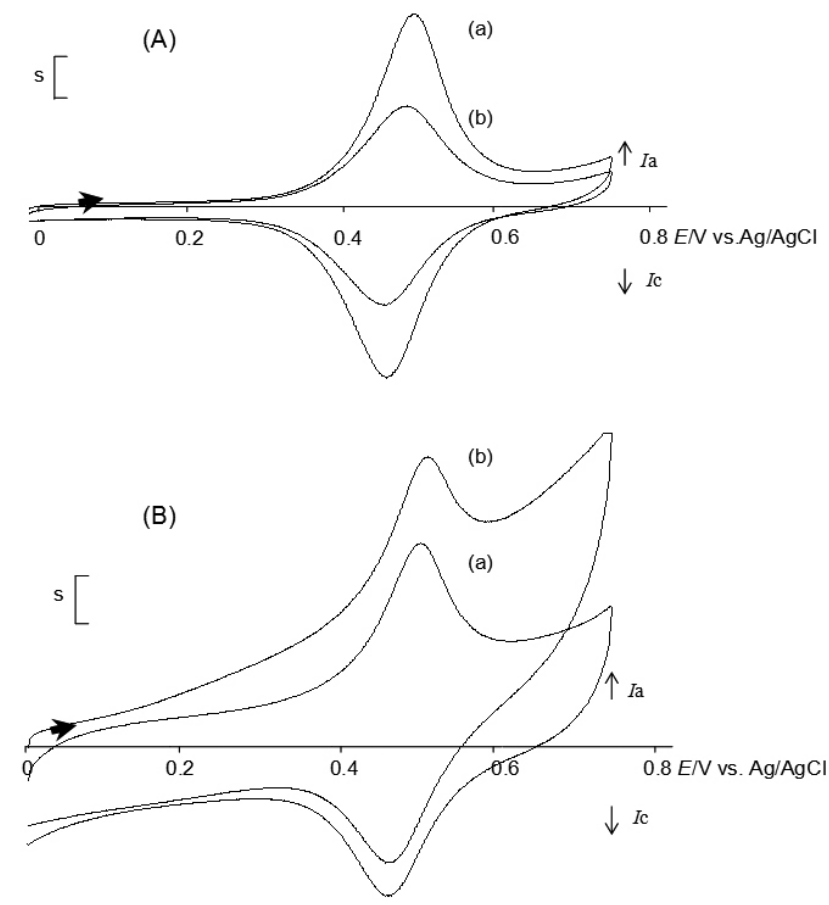

Figure 3. Cyclic voltammograms (scan rate $50 \mathrm{mV} \mathrm{s}^{-1}$ ) recorded in $10^{-1}$ $\mathrm{M}$ aqueous $\mathrm{LiClO}_{4}$. (A) ClpolyFc glassy carbon modified electrodes $(3 \mathrm{~mm}$ diameter); curve (a): $\boldsymbol{\Gamma}=9.2 \times 10^{-10} \mathrm{~mol} \mathrm{~cm}^{-2}$ in the absence and curve (b) in the presence of $10^{-3} \mathrm{M} \mathrm{H}_{2} \mathrm{AsO}_{3}^{-}$; scale $\mathrm{s}=1 \mu \mathrm{A}$. (B) Cyclic voltammograms of C|polyFc- $\mathrm{Pt}^{0}$ glassy carbon modified electrodes ( $3 \mathrm{~mm}$ diameter); curve (a): $\boldsymbol{\Gamma}$ $=9.2 \times 10^{-10} \mathrm{~mol} \mathrm{~cm}^{-2}$, in the absence and curve (b) in the presence of $10^{-3} \mathrm{M}$ $\mathrm{H}_{2} \mathrm{AsO}_{3}^{-}$; scale $\mathrm{s}=2 \mu \mathrm{A}$.

The analysis of the electrochemical response of a C/polyFc electrode $(\boldsymbol{\Gamma}$ $\left.=9.2 \times 10^{-10} \mathrm{~mol} \mathrm{~cm}^{-2}\right)$ towards $\mathrm{H}_{2} \mathrm{AsO}^{-}{ }^{-}$oxidation was achieved from cyclic voltammetry experiments (see Figure 4). Well defined curves are obtained in presence or in absence of $\mathrm{H}_{2} \mathrm{AsO}_{3}^{-}$. In $\mathrm{H}_{2} \mathrm{AsO}_{3}^{-}$-free aqueous solution, the signal corresponding to $\mathrm{Fc} / \mathrm{Fc}^{+}$redox couple observed at $+0.46 \mathrm{~V}$ (see Figure 4 curve a) progressively decreases in the presence of increasing amount of $\mathrm{H}_{2} \mathrm{AsO}_{3}^{-}$, from $1 \times 10^{-4} \mathrm{M}$ to $1 \times 10^{-3} \mathrm{M}$, (see Figure 4 curve $\mathrm{b}, \mathrm{c}, \mathrm{d}$, e) by the ion pairs formed between alkylammonium groups and $\mathrm{H}_{2} \mathrm{AsO}_{3}^{-}$anions.

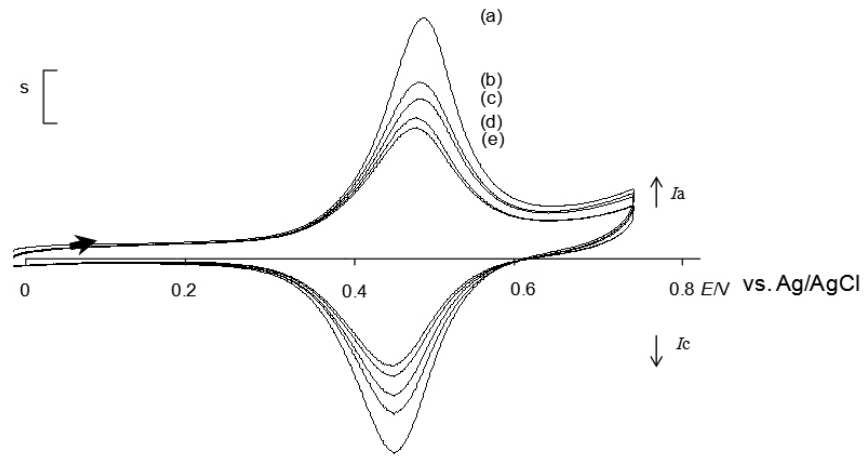

Figure 4. Cyclic voltammograms recorded in $10^{-1} \mathrm{M}$ aqueous $\mathrm{LiClO}_{4}$ at a ClpolyFc electrode ( $3 \mathrm{~mm}$ diameter; $\boldsymbol{\Gamma}=9.2 \times 10^{-10} \mathrm{~mol} \mathrm{~cm}^{-2}$ ) in absence of $\mathrm{H}_{2} \mathrm{AsO}_{3}^{-}$(curve a) and in the presence of increasing amounts of $\mathrm{H}_{2} \mathrm{AsO}_{3}^{-}=10^{-4}$ $\mathrm{M}^{2}$ (curve b), $2.5 \times 10^{-4} \mathrm{M}$ (curve c), $5 \times 10^{-4} \mathrm{M}$ (curve d) and $10^{-3} \mathrm{M}$ (curve e); scan rate $50 \mathrm{mV} \mathrm{s}^{-1}$. Scale $\mathrm{s}=1 \mu \mathrm{A}$.

Figure $5 \mathrm{~A}$ shows the cyclic voltammetric response (scan rate $50 \mathrm{mV} \mathrm{s}^{-1}$ ) of a ClpolyFc- $\mathrm{Pt}^{0}$ modified electrode when adding increasing amounts of $\mathrm{H}_{2} \mathrm{AsO}_{3}^{-}$, from $1 \times 10^{-4} \mathrm{M}$ to $3 \times 10^{-3} \mathrm{M}$, in $10^{-1} \mathrm{M} \mathrm{LiClO}$ aqueous solution. The $\mathrm{CV}$ curves show a progressive increase in the oxidation peak for the ferrocene moieties $(E$ $=+0.48 \mathrm{~V})$. This behavior is probably due to the catalytic oxidation of arsenite by the metal particles incorporated into the polymer film. The concentration of arsenite can be monitored at $+0.48 \mathrm{~V}$, i.e. at a lower potential than polypyrrolemetal nanocomposites ${ }^{19,20}$ and Pt nanoparticles modified carbon electrode ${ }^{14}$ reported previously in literature.
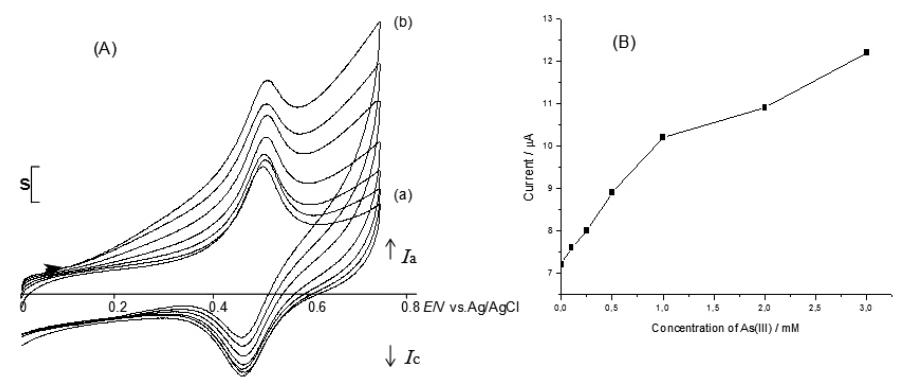

Figure 5. (A) Cyclic voltammograms recorded in $10^{-1} \mathrm{M}$ aqueous $\mathrm{LiClO}_{4}$ at a ClpolyFc-Pt electrode ( $3 \mathrm{~mm}$ diameter; $\boldsymbol{\Gamma}=9.2 \times 10^{-10} \mathrm{~mol} \mathrm{~cm}^{-2}$ ) in the presence of increasing amounts of As(III), from $10^{-4} \mathrm{M}$ (curve a) to $3 \times 10^{-3} \mathrm{M}$ (curve b); scan rate $50 \mathrm{mV} \mathrm{s}^{-1}$; Scale $\mathrm{s}=2 \mu \mathrm{A}$. (B) Plot of main peak currents vs. the concentration of $\mathrm{As}(\mathrm{III})$.

The plot of the peak current vs. the concentration of As(III) is presented in Figure $5 \mathrm{~B}$. The peak height increased linearly with the addition of arsenite until $1 \times 10^{-3} \mathrm{M}$ of arsenic species. Above of this concentration the current did not reach the linearity and loss the detection properties. The calibration slope was $0.004 \mathrm{~A} \mathrm{M}^{-1}$ and the limit of detection (LOD ${ }^{21}$ ) was calculated to be 1.45 $\times 10^{-4} \mathrm{M}(10.4 \mathrm{ppm})$. Stability of the C|polyFc-Pt ${ }^{0}$ modified electrodes was investigated only to a limited extent and showed marginal loss of activity (less than $10 \%$ ) after a series of at least 10 experiments.

Similar voltammetric responses to increasing amounts of As(III) were obtained using C $\mid$ polyFc- $\mathrm{Pd}^{0}$ modified electrodes (see Figure 6). This results were obtained with polymer films synthesized using polymerization charge of $1 \mathrm{mC}\left(\boldsymbol{\Gamma}=8.4 \times 10^{-10} \mathrm{~mol} \mathrm{~cm}^{-2}\right)$. In these experimental conditions, the oxidation potential for arsenite detection was increasing constantly from $+0.48 \mathrm{~V}$ to +0.7 $\mathrm{V}$ (see Figure $6 \mathrm{~B}$ ). The calibration slope was $0.002 \mathrm{~A} \mathrm{M}^{-1}$ and the limit of detection (LOD) was calculated to be $2.44 \times 10^{-4} \mathrm{M}(17.5 \mathrm{ppm})$. The ClpolyFc$\mathrm{Pd}^{0}$ presented lowest sensibility towards arsenite detection showing the highest LOD of the modified electrodes studied in this work. 

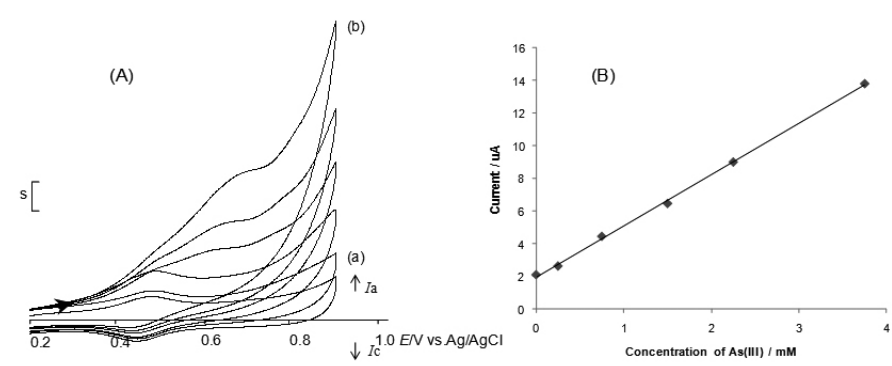

Figure 6. (A) Cyclic voltammograms recorded in $10^{-1} \mathrm{M}$ aqueous $\mathrm{LiClO}_{4}$ at a ClpolyFc-Pd ${ }^{0}$ electrode ( $3 \mathrm{~mm}$ diameter; $\boldsymbol{\Gamma}=8.4 \times 10^{-10} \mathrm{~mol} \mathrm{~cm}^{-2}$ ) in the presence of increasing amounts of As(III), from $2.5 \times 10^{-4} \mathrm{M}$ (curve a) to 3.75 $\times 10^{-3} \mathrm{M}$ (curve b); scan rate $50 \mathrm{mV} \mathrm{s}^{-1}$. (B) Plot of main peak currents vs. the concentration of As(III); scale $\mathrm{s}=2.5 \mu \mathrm{A}$.

\section{CONCLUSIONS}

This study demonstrates that platinum and palladium metal-poly ferrocenyl alkylammonium nanocomposites film modified electrodes $\left(\mathrm{C} \mid\right.$ polyFc- $\mathrm{Pt}^{0}, \mathrm{C} \mid$ polyFc-Pd $\left.{ }^{0}\right)$ present electrocatalytic properties towards the oxidation of arsenite to arsenate, in spite of the small amount of metal catalyst electroprecipitated in the polymer films.

In the case of $\mathrm{C} \mid$ polyFc modified electrode, the electrochemical response of the ferrocene center was deeply modified in presence of $\mathrm{H}_{2} \mathrm{AsO}_{3}^{-}$anions, the $\mathrm{CV}$ curves showing a strong decrease in the electroactivity of the film. It was thus concluded that cationic ClpolyFc film presents affinity toward $\mathrm{H}_{2} \mathrm{AsO}_{3}^{-}$.

After incorporation of a small amount of platinum or palladium into the polyFc films, the ClpolyFc- $\mathrm{Pt}^{0}$ or $\mathrm{Pd}^{0}$ composite film modified electrodes showed catalytic activity towards oxidation of $\mathrm{As}(\mathrm{III})$ to $\mathrm{As}(\mathrm{V})$, revealed by a clear increase in the anodic current. These results are promising for the development of efficient anodes to perform the electro-oxidation of As(III) to $\mathrm{As}(\mathrm{V})$ at lower potentials.

\section{ACKNOWLEDGEMENTS}

The authors thank FONDECYT (Grant No 11140324) and CIPA, Chile. DPO thank the project PMI-CD InES of Universidad Andrés Bello.

\section{REFERENCES}

1.- R.S. Braman, Arsenic in the environment. E.A. Woolson, editor. Arsenical pesticides, ACS Ser. 1975.

2.- R.J. Sullivan, Preliminary air pollution survey of arsenic and its compounds. A literature review. National Air Pollution Control Administration Publication No. APTD, Raleigh, NC, 1969.

3.- J.O. Nriagu, J.M. Azcue, Arsenic historical perspectives. In: J.O. Nriagu editor. Arsenic in the Environment. Part 1: Cycling and Characterization. New York: John Wiley and Sons, Inc, 1990.

4.- D.K. Nordstrom, Science, 296, 2143, (2002).

5.- E.A. Woolson, W.H. Lederer, R.J. Fensterheim editors. Industrial, Biomedical and Environmental Perspective. New York: Van Nostrand Reinhold Company, 1983.

6.- W.T. Piver, Environ. Health, 6, 1, (1983).

7.- E.A. Woolson, Environ. Health, 6, 51, (1983).

8.- WHO. Arsenic Compounds, Environmental Health Criteria 224, 2nd ed., Geneva: World Health Organization, 2001.

9.- U.S. Environmental Protection Agency. Interim Primary Drinking Water Standards. Fed. Reg. 1975.

10.- A. Cavicchioli, M. A. La-Scaela, I. G. R. Gutz, Electroanalysis, 16, 697, (2004).

11.- D. Q. Hung, O. Nekrassova, R. G. Compton, Talanta, 64, 269, (2004).

12.- J. A. Lown, D. C. Johnson, Anal. Chim. Acta, 116, 41, (1980).

13.- D. G. Williams, D. C. Johnson, Anal. Chem., 64, 1785, (1992).

14.- X. Dai, R. G. Compton, Analyst, 131, 516, (2006).

15.- O. Reynes, G. Royal, E. Chaînet, J-C. Moutet, E. Saint-Aman, Electroanalysis 15, 65, (2003).

16.- A. Deronzier, J-C. Moutet, Coord. Chem. Rev. 147, 339, (1996).

17.- O. Reynes, J-C. Moutet, G. Royal, E. Saint-Aman, Electrochim. Acta. 49, 3727, (2004).

18.- A. Ion, I. Ion, A. Popescu, M. Ungureanu, J-C. Moutet, E. Saint-Aman,
Adv. Mater. 9, 711, (1997).

19.- J. Sánchez, B.L. Rivas, S.A. Pooley, L. Basáez, E. Pereira, I. PignotPaintrand, C. Bucher, G. Royal, E. Saint-Aman, J-C. Moutet. Electrochim. Acta, 55, 4876, (2010).

20.- J. Sánchez, B. Butter, B.L. Rivas, L. Basáez, P. Santander, J. Appl. Electrochem. 45, 151, (2015).

21.- D.A. Skoog, Principles of Instrumental Analysis, Ed. F. J Holler, T. A. Nieman, Saunders College Publishing, Philadelphia, 1998. 